\title{
EFFECT OF DAIDZEIN 120 MG SUPPLEMENTATION TO MENOPAUSAL SYMPTOMS AND QUALITY OF LIFE IN NON EQUOL PRODUCER WOMEN
}

\author{
MUHARAM R*, BUDIMAN B, RACHMAN IA, NIRMALASARI RA \\ Department of Obstetrics and Gynecology, Division of Reproductive Immuno-endocrinology, Faculty of Medicine, Cipto Mangunkusumo \\ General Hospital, Universitas Indonesia, Jakarta, Indonesia. Email: rmuharam@yahoo.com
}

Received: 11 July 2016, Revised and Accepted: 25 August 2016

\section{ABSTRACT}

Objectives: To investigate and compare symptom changes and quality of life (QOL) in non equol producer postmenopausal women after consuming daidzein supplementation.

Methods: This was a single randomized clinical trial. It involved menopausal women. They were divided into two groups, one received placebo that contains calcium glycerophosphate $500 \mathrm{mg}$, vitamin D3 35 IU and daidzein group contain daidzein $120 \mathrm{mg}$, contain calcium glycerophosphate $500 \mathrm{mg}$, vitamin D3 140 IU for 8 weeks. Plasma equol was measured before supplementation. Menopause QOL (MenQOL) questionnaires have been utilized in the beginning and the end of treatment to assess the QOL.

Results: A total of 41 women age 45-63 years old were included in this trial, 19 (47.5\%) of them receive daidzein supplementation and others received control treatment. Menopausal symptoms decreased but not statistically significant compare to control group.

Conclusion: About 8 weeks daidzein supplementation was not statistically improved MenQOL status in non equol producer postmenopausal women.

Keywords: Menopause, Quality of life, Menopausal symptom, Isoflavone, Daidzein, Menopause quality of life.

(C) 2016 The Authors. Published by Innovare Academic Sciences Pvt Ltd. This is an open access article under the CC BY license (http://creativecommons. org/licenses/by/4. 0/) DOI: http://dx.doi.org/10.22159/ajpcr.2016.v9s3.14023

\section{INTRODUCTION}

Menopause is defined as cessation of menstruation, which represents the end of ovulation, causes reduction in estradiol production [1,2]. Average menopausal age varies in range between 50 and 52 years old [1]. By 2012 in Indonesia, 44\% of women underwent menopausal phase by the age of 48-49 years old [3]. If life expectancy in Indonesian women was 73 years old, it implied women would spent one-third of her life cycle within menopausal phase, dealing with its consequences. This triggers awareness toward action to elevate women's quality of life (QOL) in this concerning period $[3,4]$.

Vasomotor symptoms, physical, psychological, and sexual dysfunction became major complains due to physiological changes during menopause [4-6]. Duration and intensity of these symptoms vary among women. In European countries, complaints of sleep disturbance, depression, and vasomotor symptoms frequently found. On the other hand, Australian women mostly experience vasomotor symptoms and sexual dysfunction [7]. Interestingly, studies in Asia held in 2006 discovered that vasomotor symptoms were not the major concern but muscular and joint problems followed by memory derangement [8]. In Indonesia, only $5 \%$ of women complained of hot flushes, while $93 \%$ had joint muscular symptoms [8].

Epidemiology studies concluded Asian women, who consumed soy, experience lesser menopausal symptoms compared to Western women [9-13]. Soybean possesses Daidzein, one form of isoflavone substance. Within intestines, daidzein degradation conducted by intestinal microbes and changed into main metabolite substance, equol. Equol has estrogen-like structure and its affinity is greater toward beta estrogen receptor [14-16].

To overcome climacteric symptoms, some women chose to have hormonal or non-hormonal treatment [17-20]. Despite its subtle advantage, many Asian women prefer to consume pill of natural substance rather than hormonal pill to cure the according symptoms [17]. Even though hormonal therapy is the most effective way to reduce climacteric symptoms, some women are reluctant to undergo hormonal treatment due to society belief that it may cause cancer; the high spending cost of hormonal treatment interferes tendency to choose another alternative, such as herbal [18-23]. Asian Menopause Survey in 2010 declared that only 19\% from 1000 menopause women have hormone pill as their chosen treatment [17].

Soy-consuming habit forms a hypothesis that Asian women has ability to produce equol from soybean daidzein isoflavone which effects positively in reducing climacteric symptoms [11]. The study by Ishiwata, in 2009, stated that equol supplementation for 12 weeks significantly reduces mood alteration symptoms due to menopause compared to control group consisted of pre- and post-menopause [9]. Usage of daidzein supplementation is to elevate QOL in menopausal women who experience climacteric symptoms without worrying side effects that may occur unlike hormonal treatment [24].

\section{METHODS}

This research was randomized controlled trial and subjects were into two groups. The subjects received randomized allocation of treatment, calcium glycerophosphate $500 \mathrm{mg}+$ vitamin D3 35 IU as control group, and calcium glycerophosphate $500 \mathrm{mg}+$ vitamin D3 140 IU along with daidzein $120 \mathrm{mg}$ as treatment group for 8 weeks. This was a singleblind researchers acknowledge subject allocation and subjects did not aware of which group they were belong.

Drug had given every day and drug administration monitored by field coordinator to each respondent to minimalize compliance bias. In initial and end of treatment, patient fulfills the Menopause QOL (MenQOL) questionnaire, after being translated and validated, 
based on their actual complaint. Research conducted in November 2015-March 2016.

The subjects were women between 45 and 65 years old who underwent natural menopausal state had no menstruation at least 12-month after last period. Respondents who had been actively smoking, the previously under hormonal therapy for the last 6 weeks before test were taken, allergic to drug substances, liver and/or renal dysfunction, history of breast, endometrium, and/or cervix were excluded.

The samples enrolled by consecutive sampling. Researcher obtained subjects from local menopause association and each had symptoms according to questionnaire filled by subject until reach targeted number of sample and used block randomization. After consenting, peripheral blood was taken to measure daidzein and equol level using HPLC analysis. Intention to treat method was implemented in this research. This research was approved by Ethic Committee in Faculty of Medicine, Universitas Indonesia, Cipto Mangunkusumo Hospital.

\section{RESULTS}

A total of 41 respondents filled out questionnaire given and passed inclusion criteria. One respondent rejected consent. Daidzein supplementation was given to 19 subjects (47.5\%) and 21 subjects received control tablet (Table 1).

During research, four subjects dropped out treatment. There were no side effects reported from treatment group. From these selected samples, none was equol producers (Table 2).

From characteristic demography table, respondents' median age was 53-year-old in control group and 57-year-old in the treatment group with age of menopause consecutively were 50-49 years old. Mos disturbing climacteric symptoms were physical domain. Based on

Table 1: Subject characteristics

\begin{tabular}{|c|c|c|c|}
\hline Variables & Control $(n=21)$ & Daidzein $(n=19)$ & p value \\
\hline Median age & $53(45-60)$ & $57(46-63)$ & $0.22^{*}$ \\
\hline Body mass index & $25.8(18.77-42.19)$ & $26.45(21.3-33.23)$ & $0.95^{*}$ \\
\hline Parity & $2.89 \pm 1.04$ & $2.78 \pm 1.18$ & $0.77^{*}$ \\
\hline $\begin{array}{l}\text { Age of last } \\
\text { menstruation }\end{array}$ & $50(38-54)$ & $49(43-55)$ & $0.48^{*}$ \\
\hline \multicolumn{4}{|l|}{$\begin{array}{l}\text { menstruation } \\
\text { Education (\%) }\end{array}$} \\
\hline Low & $1(4.7)$ & $4(21.1)$ & $0.21^{* *}$ \\
\hline Middle & $18(85.7)$ & $12(63.2)$ & \\
\hline High & $2(9.6)$ & $3(15.7)$ & \\
\hline \multicolumn{4}{|l|}{ Soy } \\
\hline \multicolumn{4}{|l|}{ consumption (\%) } \\
\hline Never & $0(0)$ & $0(0)$ & $0.29 * *$ \\
\hline 1-2 days/weeks & $8(44.4)$ & $5(27.8)$ & \\
\hline$>2$ days/weeks & $18(55.6)$ & $13(56.5)$ & \\
\hline \multicolumn{4}{|l|}{$\begin{array}{l}\text { Menopause } \\
\text { duration (years) }\end{array}$} \\
\hline$<5(\%)$ & $13(61.9)$ & $15(78.9)$ & $0.24^{* *}$ \\
\hline$\geq 5(\%)$ & $8(38.1)$ & $4(21.1)$ & \\
\hline
\end{tabular}

Data were normally distributed and provided in mean \pm SD; data were not normally distributed would be provided in median (min-max): Categorical data were provided in percentage. ${ }^{*}$ Mann-Whitney test, ${ }^{* *}$ Chi-square test

Table 2: Respondents laboratory profile

\begin{tabular}{llll}
\hline Equal status & Control $(\mathbf{n = 2 1})$ & Daidzein $(\mathbf{n = 1 9 )}$ & p value \\
\hline $\begin{array}{l}\text { Daidzein } \\
\text { Equol }\end{array}$ & $0.5(0.5-35.73)$ & $0.5(0.5-0.5)$ & $0.091^{*}$ \\
producers (\%) & & & \\
$\quad$ Yes & $0(0)$ & $0(0)$ & - \\
$\quad$ No & $21(100)$ & $19(100)$ & \\
\hline
\end{tabular}

Data were normally distributed and provided in median (min-max); categorical data were provided in percentage. *Mann-Whitney test
MenQOL questionnaire, joint and muscular pain became the most disturbing complaint. There was no significant difference found in menopausal symptoms in control and treatment groups before intervention (Table 3).

Even though participants were not equol producers, research observed significant reduction clinically and statistically from menopause complaint score in all domains in the treatment group after 8 weeks supplementation (Table 4).

This phenomenon did not occur in control group. Yet, menopause score reduction between before and after supplementation did not statistically significant compared to control group with $\mathrm{p}>0.05$ (Table 5).

\section{DISCUSSION}

Based on descriptive data, the most complained climacteric symptoms were physical domain, followed by sexual, vasomotor, and psychosocial symptoms. $87.5 \%$ of respondents had experienced joint and muscular pain. Same result was also seen in the study by Pan-Asia Menopause, which stated that $86.3 \%$ of Asian women underwent joint and muscular problem during menopause $[8,24,25]$. Multivariate analysis by Kalarhoudi mentioned that frequent exercise, physical activity, educational background, satisfaction in family life, income, age, and duration of menopause were influencing factors that determine quality life of menopausal women [26].

Referred to Hong, around 50-60\% of Asian women produced equol. Subject consumed soy-contain diet at least twice a week in average although it was not be recorded on food recall. Yet, interestingly, laboratory examination could not detect any equol in blood plasma,

Table 3: Initial complaints characteristics

\begin{tabular}{lllll}
\hline $\begin{array}{l}\text { Domain per } \\
\text { Group }\end{array}$ & $\begin{array}{l}\text { Complaint } \\
\text { score }\end{array}$ & Difference & CI 95\% & p value \\
\hline $\begin{array}{l}\text { Vasomotor } \\
\text { Before }\end{array}$ & $3(0-10)$ & $1.73( \pm 2.84)$ & $0.36-3.10$ & $0.016^{*}$ \\
$\quad \begin{array}{l}\text { After } \\
\text { Psychosocial }\end{array}$ & & & & \\
$\quad \begin{array}{l}\text { Before } \\
\text { After }\end{array}$ & $8(1-21)$ & $5.42( \pm 6.03)$ & $2.51-8.32$ & $0.001^{*}$ \\
$\begin{array}{c}\text { Physical } \\
\text { Before }\end{array}$ & $24(6-48)$ & $11.84( \pm 15.21)$ & $4.50-19.17$ & $0.003^{*}$ \\
$\quad$ After & $13(0-33)$ & & & \\
$\begin{array}{c}\text { Sexual } \\
\text { Before }\end{array}$ & $4(0-12)$ & $2.47( \pm 2.15)$ & $1.09-3.84$ & $0.001^{*}$ \\
$\quad$ After & $2(0-13)$ & & & \\
Altogether & & & & \\
$\quad \begin{array}{l}\text { Before } \\
\text { After }\end{array}$ & $41.73( \pm 22.81)$ & $21.47( \pm 22.79)$ & $10.48-32.46$ & $0.001^{*}$ \\
\hline
\end{tabular}

Data were normally distributed and provided in median (min-max); categorical data be provided in percentage. * paired T test significant if $\mathrm{p}$ value $<0.05$. CI: Confidence interval

Table 4: Score differences per symptoms before and after daidzein supplementation

\begin{tabular}{llll}
\hline Variables & Control $(\mathbf{n = 2 1})$ & Daidzein $(\mathbf{n = 1 9 )}$ & p value \\
\hline Vasomotor & $2(0-12)$ & $3(0-10)$ & $0.36^{*}$ \\
Psychosocial & $6(0-28)$ & $8(1-21)$ & $0.37^{*}$ \\
Physical & $21(1-73)$ & $24(6-48)$ & $0.45^{*}$ \\
Sexual & $2(0-15)$ & $4(0-12)$ & $0.36^{*}$ \\
\hline Data regarding complain domain before and after treatment was not normally \\
distributed, thus be provided in median (min-max), data with normal \\
distribution be provided in mean ( \pm SD). Score differences were normally \\
distributed, thus be provided in mean ( \pm SD). Score differences analysis using \\
paired t-test. CI: Confidence interval, *: Mann Whitney test for every p value, \\
significant if p<0.05
\end{tabular}


Table 5: Score differences per symptoms between daidzein supplementation and control

\begin{tabular}{llll}
\hline & Score differences & CI 95\% & p value \\
\hline Vasomotor & & & \\
$\quad$ Daidzein & $-1.7( \pm 2.84)$ & $-1.5-2.55$ & 0.62 \\
$\quad$ Control & $-1.2( \pm 3.49)$ & & \\
Psychosocial & & $-2.6-6.87$ & 0.36 \\
$\quad \begin{array}{l}\text { Daidzein } \\
\text { Control }\end{array}$ & $-5.4( \pm 6.03)$ & & \\
Physical & $-3.2( \pm 8.43)$ & $-8.41-15.24$ & 0.56 \\
$\quad \begin{array}{l}\text { Daidzein } \\
\text { Control }\end{array}$ & $-11.84( \pm 15.21)$ & & \\
Sexual & $-8.42( \pm 20.95)$ & $-1.22-4.07$ & 0.28 \\
$\quad \begin{array}{l}\text { Daidzein } \\
\text { Control }\end{array}$ & $-2.47( \pm 2.85)$ & & \\
Altogether & $-1.04( \pm 5.00)$ & $-11.2-26.24$ & 0.42 \\
$\quad \begin{array}{l}\text { Daidzein } \\
\text { Control }\end{array}$ & $-21.47( \pm 22.79)$ & & \\
\hline
\end{tabular}

Data regarding complaint score before and after treatment was not normally distributed and provided in median (min-max). Score differences has no normal distribution, therefore analysis was using Wilcoxon test. CI: Confidence interval

therefore all participants were in homogen category, the equol non producer group [26,27]. Setchell stated that duration and amount of daidzein-containing food, type of intestinal microbiota population, such as bacteria with ability to reduce sulfa, amount of polyunsaturated fatty acid, and vitamin $\mathrm{A}$ and $\mathrm{E}$ in food influenced level of equol in vivo. Elimination of equol within plasma was 7-8 hrs [28]. This may be the reason the previous studies conducted "challenge" by giving soycontaining food prior examining respondent's equol level just to be assessed by urine collection or blood withdraw. Even so, the previous similar study by Botefilia et al., using isoflavone $120 \mathrm{mg}$ without prior soy challenge, $62 \%$ of respondents were equol producers before supplementation be given [29].

The food recall was not conducted in this research and this raised bias because contain of substance could not be measured quantitatively. Equol level after supplementation was not measured, thus researcher could not detect changes in equol level. Yet, study by Botefilia et al. stated that there were no significant changes found in equol level between equol-producer and non equol producer before and after supplementing $120 \mathrm{mg}$ daidzein for 6 weeks [29].

After 8 weeks of treatment and observation, no side effect occurred in supplementing daidzein $120 \mathrm{mg} /$ day. Until recent, no studies had shown any side effect by taking daidzein supplementation. High doses administration of phytochemical shown no effective effect or may not safeand Ikegami's study showed high-dose isoflavone (1 g per kg body weight) in pregnant mouse related to low birth weight to the fetus [30,31]. Usage of plant-based derived preparations, such as soy isoflavone needs further investigations to reveal its real pharmacological and physiological effect for number of dosage in certain period of administration [32].

MenQOL assessment of daidzein group showed reduction for 1.73 $( \pm 2.84)$ point in vasomotor domain with CI 95\% 0.36-3.10, and $\mathrm{p}=0.016$. This implied that if measurements re-conduct in population, menopause score difference before and after 8 weeks supplementation of daidzein $120 \mathrm{mg}$, calcium glycerophosphate $500 \mathrm{mg}$, and vitamin D 140 IU would range between 0.36 and 3.10. Significant reduction occurred in all symptom domains, including overall QOL, as listed in Table 4. However, this result did not occur in control group. Based on research conducted by Basaria, consumption of $20 \mathrm{~g}$ soy in 12 weeks decreased menopausal symptoms in four MenQOL domains [33].

Other study concluded that most Asian women complained less and milder regarding menopausal symptoms compared to Europeans. Phytoestrogen consumption was believed as the root of this phenomenon [34]. Even though in average, participants consumed soy- containing food more than 2 days a week, lab found to equol in blood plasma. This portrayed that participants had no ability to transform soy isoflavones into its metabolites, equol which is a metabolic degradation by intestinal flora that has proven possesses beneficial impact in menopausal physiological changes [35]. Weakness of this report was no food recall data to measure soy consumption per day quantitatively.

This study's strength compared to the previous studies was control group also received active substance due to respondents were patients with complaints. The patient compliance was be guaranteed because field coordinator distributed pills every day and attended pills administration per person. Almost no bias in filling out questionnaires, researchers accompanied each participant and explained each given question. The study analysis with intention to threat, so those who dropped out study remained involve in statistical analysis. Analytical method provided non-bias inspection regarding efficacy from intervention until treatment compliance. The patient compliance in this study represents patient compliance in the community.

\section{CONCLUSION}

Research found physical domain, joint and muscular pain, was the most complained menopausal symptoms. According to result, complaints of menopausal symptoms were reduced insignificantly after soy germ isoflavone daidzein for 8 weeks compared to control group. Trial did not record any side effects during supplementation of daidzein $120 \mathrm{mg}$ glycerophosphate $500 \mathrm{mg}$, and vitamin D 140 IU. Further investigation is important to understand other factors that may affect ability to produce equol metabolites other than soy consumption.

\section{REFERENCES}

1. Gold EB. The timing of the age at which natural menopause occurs Obstet Gynecol Clin North Am 2011;38(3):425-40.

2. Fritz MA, Speroff L. Menopause and perimenopausal transision. In Seigafuze S, editor. Clinical Gynecology, Endocrinology and Infertility. $8^{\text {th }}$ ed. Philadelphia, PA: Lippincott Williams \& Wilkins; 2011. p. 673-748.

3. Badan Pusat Statistik B, Kemenkes, ICF International. Survey Demografi Kesehatan Indonesia 2012. Jakarta, Indonesia: BPS, BKKBN, Kemenkes, ICF International; 2013.

4. Mohammadalizadeh Charandabi S, Rezaei N, Hakimi S, Montazeri A, Taheri S, Taghinejad H, et al. Quality of life of postmenopausal women and their spouses: A community-based study. Iran Red Crescent Med J 2015;17(3):e21599.

5. ACOG Practice Bulletin No 141: Management of menopausal symptoms. Obstet Gynecol 2014;123(1):202-16.

6. Grant MD, Marbella A, Wang AT, Pines E, Hoag J, Bonnell C, et al. Menopausal Symptoms: Comparative Effectiveness of Therapies. Rockville, MD: Agency for Healthcare Research and Quality (US); 2015

7. Makara-Studzińśka MT, Kryś-Noszczyk KM, Jakiel G. Epidemiology of the symptoms of menopause-an intercontinental review. Prz Menopauzalny 2014;13(3):203-11.

8. Haines CJ, Xing SM, Park KH, Holinka CF, Ausmanas MK. Prevalence of menopausal symptoms in different ethnic groups of Asian women and responsiveness to therapy with three doses of conjugated estrogens/ medroxyprogesterone acetate: The Pan-Asia Menopause (PAM) study. Maturitas 2005;52(3-4):264-76.

9. Ishiwata N, Melby MK, Mizuno S, Watanabe S. New equol supplement for relieving menopausal symptoms: Randomized, placebo-controlled trial of Japanese women. Menopause 2009;16(1):141-8.

10. Kok L, Kreijkamp-Kaspers S, Grobbee DE, Lampe JW, van der Schouw YT. A randomized, placebo-controlled trial on the effects of soy protein containing isoflavones on quality of life in postmenopausal women. Menopause 2005;12(1):56-62.

11. Persky VW, Turyk ME, Wang L, Freels S, Chatterton R Jr, Barnes S, et al. Effect of soy protein on endogenous hormones in postmenopausal women. Am J Clin Nutr 2002;75(1):145-53.

12. Hooper L, Ryder JJ, Kurzer MS, Lampe JW, Messina MJ, Phipps WR, et al. Effects of soy protein and isoflavones on circulating hormone concentrations in pre- and post-menopausal women: A systematic review and meta-analysis. Hum Reprod Update 2009;15(4):423-40.

13. Atkinson C, Newton KM, Bowles EJ, Yong M, Lampe JW. 
Demographic, anthropometric, and lifestyle factors and dietary intakes in relation to daidzein-metabolizing phenotypes among premenopausal women in the United States. Am J Clin Nutr 2008;87(3):679-87.

14. Rafii F. The role of colonic bacteria in the metabolism of the natural isoflavone daidzin to equol. Metabolites 2015;5(1):56-73.

15. Utian WH, Jones M, Setchell KD. S-equol: A potential nonhormonal agent for menopause-related symptom relief. J Womens Health (Larchmt) 2015;24(3):200-8.

16. Setchell KD, Clerici C, Lephart ED, Cole SJ, Heenan C, Castellani D, et al. S-equol, a potent ligand for estrogen receptor beta, is the exclusive enantiomeric form of the soy isoflavone metabolite produced by human intestinal bacterial flora. Am J Clin Nutr 2005;81(5):1072-9.

17. Huang KE, Xu L, Nasri N, Jaisamrarn U. The Asian Menopause Survey: Knowledge, perceptions, hormone treatment and sexual function. Maturitas 2010;65(3):276-83.

18. Farquhar C, Marjoribanks J, Lethaby A, Suckling J, Lamberts Q. Long term hormone therapy for perimenopausal and postmenopausal women. Cochrane Database Syst Rev 2009;2:CD004143.

19. American College of Obstetricians and Gynecologists. ACOG Practice Bulletin no. 28: Clinical Management Guidelines for ObstetricianGynecologists. Use of botanicals for management of menopausal symptoms. Obstet Gynecol 2001;97(6):suppl 1-11.

20. Menopause Guidelines Revision Task Force A. American Association of Clinical Endocrinologists medical guidelines for clinical practice for the diagnosis and treatment of menopause. Endocr Pract 2006;12(3):315-37.

21. Aso T. Quality of Life: Asian Women and the Menopause. Med Sci Symp Ser 2002;17:353-60.

22. Anderson D, Yoshizawa T, Gollschewski S, Atogami F, Courtney M Menopause in Australia and Japan: Effects of country of residence on menopausal status and menopausal symptoms. Climacteric 2004;7(2):165-74.

23. Beral V, Reeves G, Banks E. Current evidence about the effect of hormone replacement therapy on the incidence of major conditions in postmenopausal women. BJOG 2005;112(6):692-5.

24. Abedzadeh Kalarhoudi M, Taebi M, Sadat Z, Saberi F. Assessment of quality of life in menopausal periods: A population study in Kashan, Iran. Iran Red Crescent Med J 2011;13(11):811-7.

25. Bouzari Z, Kotaneie MJ, Darzi AA, Hajian K. Menopausal symptom can be influenced by various sociodemographic factor and Qo Decrease after menopause. World Appl Sci J 2013;23(9):1221-30.

26. Hong KW, Ko KP, Ahn Y, Kim CS, Park SJ, Park JK, et al. Epidemiological profiles between equol producers and nonproducers: A genomewide association study of the equol-producing phenotype Genes Nutr 2012;7(4):567-74.

27. Song KB, Atkinson C, Frankenfeld CL, Jokela $T$, Wähälä $K$, Thomas WK, et al. Prevalence of daidzein-metabolizing phenotypes differs between Caucasian and Korean American women and girls. J Nutr 2006;136(5):1347-51.

28. Setchell KD, Brown NM, Summer S, King EC, Heubi JE, Cole S, et al. Dietary factors infuence production of the soy isoflavone metabolite S-(-)equol in healthy adults. J Nutr 2013;143(12):1950-8.

29. Botefilia. Outcome Post Daidzein Isoflavone Supplementation in Th1/2 Cytokine Level: TNFa, IL 4, IL 6, and IL 10 in Post Menopausa Women Equol Producer and Non Equol Producer. Tesis; 2015. p. 98-9.

30. Niyva A, Raja K, Kumaravel M, Sasidharan S, Seethapathy GS. Role of Nutraceutical in cancer. Int J Pharm Pharm Sci 2012;4 Suppl 4:415-20.

31. Ikegami S, Tousen Y, Ishimi Y. Possible adverse effect of soy isoflavone mixture on pregnant and lactating rats and their suckling pups. J Health Sci 2006;52(5):558-67.

32. Marmitt DJ, Bitencourt S, Silva AD, Goettert MI, Rempel C. Medicinal plants of Renisius with analgesic activity. J Crit Rev 2016;3(3):1-4

33. Basaria S, Wisniewski A, Dupree K, Bruno T, Song MY, Yao F, et al Effect of high-dose isoflavones on cognition, quality of life, androgens, and lipoprotein in post-menopausal women. J Endocrinol Invest 2009;32(2):150-5

34. Phipl HA. Hot flashes: A review of literature on alternative and complementary treatment. Altern Med Rev 2003;8(3):284-302.

35. Harrison JJ, Dankyi E, Kingsford-Adaboh R, Ishida H. Search of new leads: A closer look at the therapeutic potential of the constituents of Millettia thonningii, Millettia pachycarpa and their structural analogues. Int J Pharm Pharm Sci 2011;3(2):71-81. 